\title{
HAPPING: NATIVOS
}

DIGITALES AL SERVICIO

DE LA IMAGEN

CORPORATIVA DE

COCA-COLA

\section{Carmen Llorente Barroso}

\section{Doctoranda}

CAVP II, Facultad de Ciencias de la Información, UCM, Madrid, España. carmenllore@gmail.com

\section{Resumen}

Happing, la comunidad de la gente que se atreve a ser feliz, es la nueva propuesta de la compañía Coca-Cola para su promoción web en España; su éxito entre los nativos digitales pone de manifiesto el acierto de esta gran marca internacional, que ha sabido aprovechar la creatividad de los nativos digitales que participan en la comunidad, para dar brillo a una Imagen Corporativa Intencional de sobra solvente. Los nativos digitales que contribuyen a la creación del mágico mundo Coca-Cola, participan gustosos de la oportunidad expresiva que les brida la compañía, fascinados por la filosofía de vida que siempre ha sido bandera de la Imagen de marca de Coca-Cola, ahora alimentada y, en parte, creada por esos nativos digitales.

Nativos digitales, Hipertexto, Marketing Viral, Web 2.0, Imagen Corporativa, Coca-Cola,

Key Words

Digital natives, Hypertext, Viral Marketing, Web 2.0, Corporative Image, Coca-Cola,

\footnotetext{
Abstract

Happing, the community of the people who dares to be happy, is the new proposal from the Coca Cola Company for its web promotion in Spain; its success among the digital native reveals us the wisdom of this great international brand has could take advantage of the creativity of the digital natives that take part in the community, to give shine to a Corporate Intentional Image plenty of solvent. Digital natives who contri-

bute to the creation of the magic world Coca Cola, participate gladly of the expressive opportunity that the company gives them, fascinated by the philosophy of life that has always been

a flag of the brand Image of CocaCola, now fed and, in part, created by these digital natives.
} 


\section{Introducción}

Las sociedades actuales, las de la información audiovisual, están marcadas por las nuevas Tecnologías de la Información y la Comunicación y, muy especialmente por Internet, medio y herramienta imprescindible para las personas inquietas y curiosas que, gracias a la Red de redes, se han convertido en creadores de discursos que nacen, crecen y parecen no tener fin, aunque eventualmente mueren y su falta de estabilidad, puede llevar a considerarles efímeros.

Mencionados discursos se rescriben y reinventan, configurando hipertextos en beneficio de una comunicación dinámica que además de generar nuevos vínculos sociales, de tipo interactivo y, en cierto modo, "espectrales" (dado que no son físicamente reales), pueden también contribuir a crear una Imagen favorable a una marca o a pulir una Imagen Corporativa de sobra estable.

Tales creadores, generalmente jóvenes $\mathrm{y}$ estudiantes, son conocidos como nativos digitales, pues han nacido en la era de las comunicaciones digitales, aprovechando las ventajas que les ofrecen. Sin embargo, su labor creativa no ha pasado desapercibida para las grandes y prestigiosas marcas, quienes, en la lucha por sobresalir en un mercado saturado de ideas llamativas, han apostado por un marketing centrado en la creatividad de los consumidores no ya de los productos o servicios de estas marcas, sino más bien, del maravilloso lenguaje de la Red que les proporciona una nueva forma de expresión.

Happing es un gran ejemplo, para analizar esta característica Comunicación Corporativa, creada por los propios consumidores de la Red para sus marcas predilectas que, muy observadoras, aprovechan estas redes sociales y la creatividad de los nativos digitales para asociar determinados valores positivos, no tanto a lo que son, como a lo que pretenden transmitir que son.

Con esta propuesta, Coca-Cola no sólo consigue que los nativos digitales alimenten su filosofía y contribuyan a configurar el paraíso de felicidad con el que se identifica la marca; la compañía les convierte en autores y protagonistas indispensables de la propia historia de la marca. De este modo, la empresa de refrescos y fábrica de sueños, simplemente da el pistoletazo de salida para la creación de un espacio que la propia marca aprovechará para pulir su Imagen, pero que constituye "una conversación que la compañía mantiene con los consumidores de su marca y amantes de su ideología”. 


\section{Objetivos}

El objetivo que se persigue en este artículo es dilucidar una estrategia de marca empleada por prestigiosas compañías, que utilizan a los nativos digitales para pulir una Imagen Corporativa relativamente estable, recurriendo a redes sociales preexistentes según lo que puede considerarse una estrategia de marketing viral, para la difusión de una idea que favorece positivamente la Imagen de esa marca, aunque no exista aparentemente intención de ello.

\section{Metodología}

Se realiza un análisis observacional de Happing, la apuesta de Coca-Cola para su promoción web en España y que la propia empresa ha definido como "la comunidad de la gente que se atreve a ser feliz".

Esos atrevidos son nativos digitales que aprovechando la oportunidad que CocaCola les ofrece, expresan sus emociones, sentimientos, aficiones... al tiempo que se consideran dignos de pertenecer a una comunidad que no es otra cosa que una estrategia de marketing encubierto, a través de la cual, la empresa de refrescos pretende ser asociada a una Imagen dinámica, atrevi$\mathrm{da}$, juvenil, alegre... como los nativos digitales que la hacen posible.

\section{Happing, la creación de un mundo nuevo: el de la gente que se atreve a ser feliz}

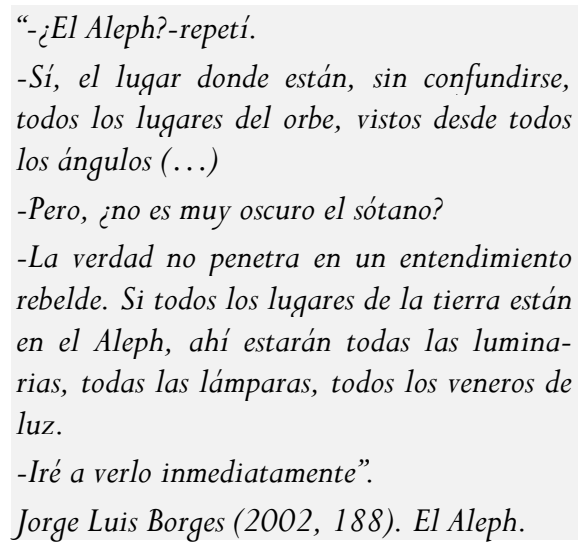
rebelde. Si todos los lugares de la tierra están en el Aleph, ahí estarán todas las luminarias, todas las lámparas, todos los veneros de luz.

-Iré a verlo inmediatamente".

Jorge Luis Borges (2002, 188). El Aleph.

De este modo, Borges definía un lugar utópico y fascinante, una fotografía viva desde la que expiar un mundo maravilloso (¿tal vez una comunidad on line?), difícil de imaginar real, pero cada vez más posible gracias a los nuevos lenguajes (por supuesto, artificiales) que utilizan esos jóvenes llamados nativos digitales.

Belén Gache (2006, 41 - 46), mantiene que cada lenguaje artificial que surge lo hace con la intención de cumplir un propósito y tiene la capacidad de generar mundos alter- 
nativos a la vez que determina la cosmovisión de los hombres que lo utilizan.

En esta misma línea Carlos Colina (2002) considera que con las formas emergentes de multimedia, el empleo del tiempo libre ha adquirido nuevas dimensiones, apuntando así que estas nuevas formas vienen a conformar una descripción de una realidad nueva y emergente: la de los nuevos mun- sus "visiones sobre la felicidad" contribuyen a crear la "comunidad de la gente que se atreve a ser feliz", apoyan su causa y, de este modo, colaboran en pulir una Imagen Intencional de sobra perfilada.

Sentimientos, sensaciones, experiencias... que giran en torno a la idea de felicidad, determinan las bases de esta fotografía viva de enorme potencial seductor para los dos que se nos brinda construir.

Happing, es uno de estos mundos; Coca-Cola lo define como "la comunidad de la gente que se atreve a ser feliz", un paraíso que sería inimaginable sin la existencia de los nativos digitales, ellos lo constituyen y lo construyen, al tiempo que con ello contribuyen a engrandecer la Imagen de la compañía de refrescos.

Estos nativos digitales pertenecen a una sociedad caracterizada por medios que permiten este novedoso lenguaje y

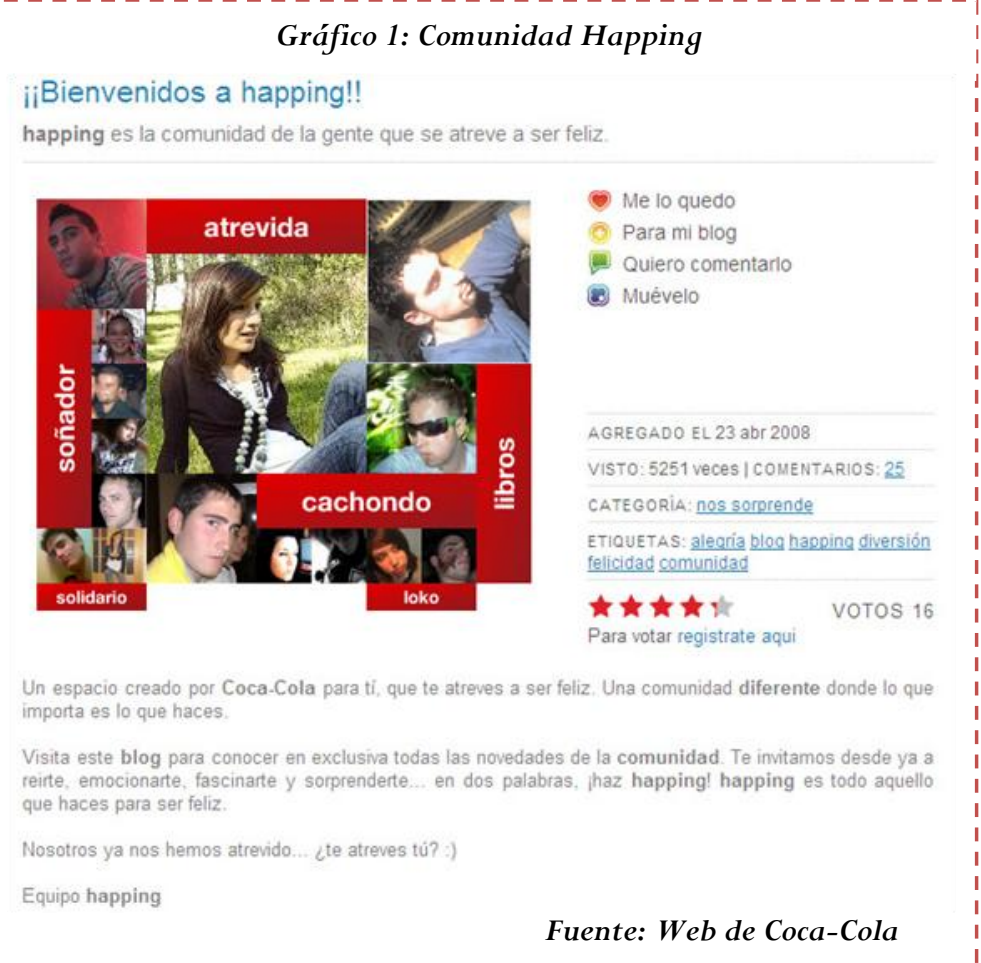
sienten pasión por configurar nuevas formas de relación a las que, las grandes empresas, saben sacar provecho. Coca-Cola da ejemplo de ello con Happing, demostrando un gran interés por beneficiarse de la interesante creatividad de estos jóvenes que con

jóvenes nativos digitales; pero, ¿qué tiene esto que ver con una compañía internacional cuyo producto estrella es un refresco de dudosa salubridad?

Aparentemente nada y, si nos detenemos un momento podría ser hasta contradicto- 
rio: ¿cómo puede hacer feliz a alguien consumir un producto poco saludable? Sin embargo, más allá de las apariencias, aunque precisamente basada en un formato visualmente (y por ello aparentemente) atractivo, la intención de la comunidad, es enganchar; la gente que entra y habla de sus atrevidas y divertidas experiencias, lo hace porque quiere ser feliz y en la comunidad se le reta a ello. El módico precio que ha de pagar quien pretenda pertenecer a tal comunidad es: su creatividad al servicio de una Imagen positiva para Coca-Cola.

Las reglas que rigen la comunidad, se ciñen al mítico y mágico universo Coca-Cola; riesgo, atrevimiento y, en conclusión diversión, configuran un paraíso en el que no tienen cabida ni las desgracias ni, tan siquiera, la realidad.

Los nativos digitales crean entonces un universo alternativo, utópico e ideal, que favorece a fomentar el universo que CocaCola lleva potenciando durante muchos años de cuidado marketing; la diferencia fundamental, es que ahora lo crean sus consumidores y, concretamente, aquellos que se sienten más fascinados por pertenecer a un mundo y contribuir a su creación, que por un producto en sí.

\section{Happing, un mundo construido como hipertexto-hipermedio}

\subsection{Aproximaciones al concepto de hipertextualidad}

Antes de aventurarnos a determinar si Happing puede considerarse un hipertexto o no, conviene presentar una definición más $\mathrm{o}$ menos precisa del hipertexto o la hipertextualidad.

El concepto de hipertexto ha sido protagonista de múltiples ensayos e investigaciones en la década de los 80 del siglo pasado y aún continúa siéndolo. La interpretación más interesante que puede extraerse de este hecho, es que mencionado concepto ha suscitado el interés de ámbitos científicos y académicos muy distintos, convirtiéndose en un vínculo de adhesión entre disciplinas tan dispares como la Literatura y la Informática.

El problema es que tantas investigaciones de ámbitos tan diversos han difuminado un concepto de hipertexto, produciéndose un caos conceptual que trataremos de aclarar para poder continuar el tema que nos ocupa.

\subsubsection{La dimensión electrónica del concepto de hipertexto}

La idea original de la definición más extendida y conocida de hipertexto es la de hipertexto electrónico y se produce en 1945 , cuando Vannevar Bush describía el dispositivo MEMEX en un artículo publicado bajo 
el título As we may think (Bush, 1945). Basándose en las posibilidades limitadas de la mente humana, en su capacidad asociativa y en el carácter relativamente permanente de los documentos que ésta puede crear, Bush idea un dispositivo capaz de lograr la velocidad y flexibilidad asociativa de la mente humana y superarla en su labor de almacenamiento.

"Consider a future device for individual use, which is a sort of mechanized private file and library. It needs a name, and, to coin one at random, "memex" will do. A memex is a device in which an individual stores all his books, records, and communications, and which is mechanized so that it may be consulted with exceeding speed and flexibility. It is an enlarged intimate supplement to his memory.

It consists of a desk, and while it can presumably be operated from a distance, it is primarily the piece of furniture at which he works. On the top are slanting translucent screens, on which material can be projected for convenient reading. There is a keyboard, and sets of buttons and levers. Otherwise it looks like an ordinary desk." (Bush, Vannevar, 1945).

De esta forma, V. Bush sienta los pilares de lo que después se conocería como el hipertexto electrónico, materia prima de una de las herramientas fundamentales en las sociedades actuales que permite la existencia de los nativos digitales y de sus obras; nos referimos a Internet.
Pese a que Vannevar Bush es el primero en idear este tipo de dispositivos, es Theodore Nelson el primero en hablar de hipertexto en un congreso organizado en 1965 para describir el sistema XANADÚ (http://xanadu.com/xuTheModel) que él mimo proyectó, refiriéndose a que durante toda nuestra vida, los seres humanos pensamos, hablamos y vivimos en forma de hipertextos y, sólo al escribir, construimos secuencias lineales de ideas (Scolari, 2003).

Treinta años después de la presentación oficial de Xanadú, llegaría World Wide Web, la biblioteca ilimitada soñada por Bush y Nelson y el medio de comunicación que permitirá la máxima expresión de los nativos digitales y las formas más inauditas de lograr una Comunicación Corporativa de alta creatividad y bajo coste.

\subsubsection{La dimensión comunicativa del concepto de hipertexto}

El hipertexto se presenta como una nueva forma de comunicación, no exclusiva de Internet, aunque su uso se haya extendido gracias a esta red.

George Landow (1997), concibe el hipertexto, en este sentido comunicativo, como un medio que conecta informaciones verbales y no verbales. La hipótesis de Landow es que el hipertexto cambiaría radicalmente las experiencias de la lectura y la escritura e, incluso, el concepto mismo de texto.

Según Landow, el hipertexto se caracteriza por dos aspectos comunicativos fundamentales: 
1. Elimina la linealidad del texto escrito, destruyendo el orden secuencial que lo caracterizaba en su forma tradicional. La no linealidad se convierte en un distintivo del hipertexto que se emparenta con una estrategia retórica inspirada en la dispositio (García García, F., 2006).

2. Reformula los roles de autor y lector, reclamando un lector más activo que, además de elegir lo que lee, tiene la oportunidad de leer como si fuera autor.

Los autores pasan parte de su tarea a los lectores, que se convierten además en creadores de una obra colectiva, en la que participan desde contextos geográficos, sociales y culturales muy diversos y en diferentes tiempos. Y todo ello facilitado por la Red de redes, aunque ésta no sea el único soporte en el que se den hipertextos.

No obstante, algunos autores prefieren matizar esta afirmación y no se muestran completamente de acuerdo con que el lector del hipertexto pueda ser, al leerlo, autor del mismo. Así por ejemplo, Espen Aarseth (2006, 92-119), en un intento por analizar no tanto lo que él considera la poética del hipertexto como su estética, manifiesta sus dudas sobre una posible coautoría del lector mientras lee el texto (Aarseth, Espen, 2006, 95-96): “... dudo que el efecto del hipertexto, en sus muchas y diversas implementaciones, pueda ser identificado singularmente como un medio para unificar lectura y escritura en un mismo proceso. (...) es justo constatar que los hipertextos que podemos leer hoy, (...), siguen funcionando dentro del esquema estándar de autor, lector y texto”. Sin embargo, el autor no deja de reconocer que el hipertexto es una nueva forma de escribir mediante enlaces activos, pero no supone una reconfiguración de la narrativa sino una alternativa, algo que explica introduciendo un concepto muy interesante, el de ergódico (Aarseth, Espen, 2006, 118):

"hace referencia a una situación en la cual una cadena de acontecimientos (un camino, una secuencia de acciones, etc.) ha sido producida por los esfuerzos no triviales de uno o más individuos o mecanismos".

Jaime Alazraki (1984) en su ensayo El texto como palimpsesto. Lectura intertextual de Borges, considera que los relatos borgianos están escritos a partir de cuatro básicos, determinando que los textos de sus cuentos funcionan como un espejo que invierte o revierte historias ya contadas, imágenes ya advertidas (Alazraki, Jaime, 1984, 282); el propio Jorge Luis Borges (1972, 130), como introducción a su relato Los cuatro ciclos, habla de estas cuatro historias:

"Cuatro son las historias. Durante el tiempo que nos queda, seguiremos narrándolas, transformadas." Jorge Luis Borges (1972, 130). Los cuatro ciclos (El oro de los tigres).

Lo verdaderamente interesante de nuestro análisis, no es determinar el número de historias que Borges relee para engendrar sus relatos, lo importante es que, la mayor parte de los acontecimientos culturales que 
nos rodean no son otra cosa que una relectura de una historia, una idea,...

El hipertexto se convierte en un nuevo lenguaje de extensas posibilidades -un atractivo laberinto- (Colina, Carlos, 2002, 51-59), capaz de permitir el discurso propio de los nativos digitales que hacen posible Happing; y mencionado discurso puede ser interpretado según tres posibilidades:

1. Como una forma específica del Lenguaje, en el que pueden diferenciarse diferentes niveles de emisión.

2. Como un conjunto de representaciones mentales que implican un contexto sociocultural (creencias, ideologías) compartido por una comunidad determinada.

3. Como una acción social contextualizada; esta es la característica más importante del hipertexto en cuanto a discurso, prevalece de forma notoria la dimensión pragmática o funcional, porque el hipertexto es acción o no es.

El hipertexto es un discurso en el que no sólo se enlazan contenidos, sino también modalidades y prácticas comunicativas alternativas, además de recursos muy diversos (Colina, Carlos, 2002, 58), por lo que el lector no sólo torna, al mismo tiempo, autor, sino también actor.

En esta línea podemos interpretar que no sólo los escritores se convierten en autores de cultura, también contribuyen con sus esfuerzos no triviales, con sus acciones, esos nativos digitales que se adentran en la aventura de participar en una comunidad abierta que se enriquece cada día con las diferentes participaciones de tales nativos, al tiempo que es plataforma de Imagen para un marca. En este caso, no estamos hablando sólo de un lector-actor que toma decisiones a lo largo de su visita-lectura en Happing, se trata de autores que contribuyen a la creación del texto.

En sus interesantes aportaciones, Alejandro Piscitelli (2002), apoyado en el concepto de cibertexto propuesto por Aarseth (1997), asegura que el cibertexto (entendido como un hipertexto dinámico) es una máquina para la producción de una variedad de expresiones (Piscitelli, Alejandro, 2002, 34). El cibertexto es, según Piscitelli, una perspectiva sobre tipos de textualidad que remite a modalidades textuales dinámicas, lo que le convierte en un hipertexto peculiar, porque en este caso, el lector dispone de instrumentos de auto-manipulación que permiten la producción y consumo mecánicos de los signos verbales (Piscitelli, Alejandro, 2002, 38). No se trata de un hipertexto en el que el lector interprete, además interviene. Generalmente, este término remite a juegos de aventuras de rol on line, pero de cualquier forma puede interpretarse como consideración esencial ligada al hipertexto (en cuanto a forma de escritura no lineal que exige un lector activo), perfectamente aplicable a Happing: la dimensión paraverbal, inalcanzable en una lectura tradicional. 


\subsubsection{La dimensión literaria $y$ filosófica del concepto de hipertexto}

Sin desprestigiar lo que se convertiría en un concepto esencial para los avances teóricos y prácticos que han hecho posible la realidad cibernética, existen otras concepciones de hipertexto más vinculadas al mágico mundo de la literatura, la creatividad, la comunicación y, consecuentemente, la Imagen Corporativa.

Entre tales ideas de hipertexto, no podemos olvidar la que nos regaló Gérard Genette que algunos, entre los que modestamente me incluyo, han relacionado con lo que finalmente somos, lo que dejamos a los que quedan y lo que se encontrarán los que vendrán, nuestro pequeño aporte personal a esa gran huella de toda la comunidad mundial a lo largo de la existencia de la humanidad: la Cultura.

Gérard Genette, en su obra Palimsesptos. La literatura en segundo grado (Genette, Gérard, 1989), ofrece una perspectiva distinta de hipertextualidad, incluyendo este concepto como una forma determinada de transtextualidad.

El autor definió la transtextualidad o transcendencia textual del texto (Genette, Gerard, 1989: 9 y ss.) como todo lo que pone al texto en relación, manifiesta o secreta, con otros textos, diferenciando cinco tipos de relaciones transtextuales:

1. Intertextualidad: Relación de copresencia entre dos o más textos.
2. Paratexto: Relación, generalmente menos explícita y más distante que, en el todo formado por una obra literaria, el texto propiamente dicho mantiene con su paratexto- título, subtítulo, intertítulos....

3. Metatextualidad: Es la relación generalmente denominada "comentario"que une un texto a otro texto que habla de él sin citarlo (convocarlo), e incluso, en el límite, sin nombrarlo.

4. Architextualidad: Relación completamente muda que, como máximo, articula una mención paratextual.

5. Hipertextualidad: Toda relación que une un texto B (hipertexto) a un texto anterior A (hipotexto) en el que se injerta de una manera que no es la del comentario.

Más adelante, el autor define el hipertexto como todo texto derivado de un texto anterior por transformación simple (diremos en adelante transformación sin más) o por transformación indirecta, (diremos imitación) y dedica a este tipo de relaciones transtextuales el resto de su obra.

Aunque centrándose en el ámbito literario, Genette perfila un concepto aplicable a muchos otros ámbitos; una interpretación válida e interesante de su propuesta es la consideración del hipertexto como huella de la humanidad a lo largo de su existencia, como si se tratase de un texto que se escribe mediante la relectura de los acontecimientos.

Es en este ámbito donde entran conceptos directamente ligados al hipertexto de Ge- 
nette pero que tratan de contextualizarlo en un ámbito superior al de la literatura.

Mariel Ortolano (2006), basándose en determinadas consideraciones de Theodore Nelson, considera que, en cierto modo, el hipertexto digital sería un sistema construido a imagen y semejanza del hipertexto literario, dando superioridad a éste sobre aquel. Considera que el hipertexto, se inventa a base de reescribir lo que ya se escribió y de una forma similar, nosotros podemos considerar que la Cultura tiene unos pilares fundamentales que siempre acaban reapareciendo.

La enorme relación que existe entre el concepto de Cultura (con toda la complejidad que entraña) y una visión del hipertexto que hemos apuntado desde el comienzo de esta parte del artículo, ha sido vislumbrada por muchos otros autores.

La Cultura da sentido o significado a nuestras vidas y, probablemente, en este camino, Pierre Lévy determina que el hipertexto es quizás la única metáfora que vale para todas las esferas de la realidad donde están en juego las significaciones (Lévy, Pierre, op. cit en Scolari, Carlos, 2003). Considera que el hipertexto es un conjunto de nudos (imágenes, gráficos, secuencias sonoras, documentos textuales,...) interconectados que, funcionalmente, puede interpretarse como un contexto propicio para la organización de conocimientos, datos o informaciones.
Mariel Ortolano (2006) hace referencia a la obra de Pierre Lévy (2000), Tecnologías de la Inteligencia, señalando la consideración del autor francés sobre que la hipertextualidad se sustentaba en dos aspectos, un tecnológico y otro metafórico. La retórica le ofreció a Lévy la clave del concepto; el autor francés determinó que el hipertexto es la metáfora de un trabajo colectivo, desarrollado por redes de máquinas y comunidades de humanos.

Calos Scolari (2003) en Qué es un hipertexto?, hace una mención interesante sobre la conferencia de Norman Meyrowitz (1989) en la Hipertext Conference de Pittburgh titulada Hypertext - Does It Reduce Cholesterol, Too?, en la que el autor venía a hacer referencia a la terrible confusión terminológica que existía sobre este tema y en la que introdujo un tema íntimamente ligado a la concepción cultural del hipertexto:

Cuando hablamos del hipertexto y del hipermedia en términos de nuestros sueños y pasiones, estamos hablando de tener la información en modo natural en la punta de nuestros dedos. (Meyrowitz, Norman, 1989, op. cit. en Scolari, Carlos, 2003).

Esta era otra forma de determinar que el hipertexto es un concepto a través del cual puede entenderse la significación de la humanidad.

Reinterpretando estas consideraciones sobre el concepto de hipertexto, podemos determinar que la Cultura es un gran hipertexto y constituye la gran metáfora de la 
huella que deja el ser humano durante su existencia. Una idea ya defendida por el filósofo argentino Alejandro Piscitelli, quien considera que, la condición metafórica del hipertexto a la que se refiere Lévy convierte al hipertexto en un concepto útil para describir la estética y la cultura de nuestro tiempo: los acontecimientos no se desenvuelven linealmente, las posibilidades narrativas son múltiples, las narrativas se desarrollan como procesos interactivos entre autor y lector (Piscitelli, Alejandro, 2003 op cit. en Ortolano, Mariel, 2006).

El compendio de los dos grandes conceptos de hipertexto (el electrónico de Theodore
Nelson y el literario de Gérard Genette), permiten a Mariel Ortolano arrojar una interesante definición de hipertexto, muy general y aplicable, como ya se ha mencionado, incluso a la propia Cultura: hipertexto es todo texto que remite a otros textos (literarios, artísticos, filosóficos), por inclusión explícita o implícita, por basarse en un modelo anterior o en varios, cuya construcción es fragmentaria-no secuencial, y que propicia, por lo tanto, una modalidad de acceso diferente a la del texto lineal, una modalidad de lectura arbórea o en profundidad (Ortolano, Mariel, 2006).

\subsection{Happing: El gran hipertexto de la felicidad}

Las nuevas exigencias a las que estamos ceñidos, en cuanto a que somos nativos digitales, nos obligan a utilizar nuevas formas de expresión y comunicación que, en esencia, logran lo mismo que logró la escritura, pero que, en expresión, consiguen otros retos al ser mucho más atractivas. Son estas nuevas tecnologías que nos proporcionan diferentes formatos comunicativos y muy variadas formas de interacción, las que llevan a algunos autores a hablar de hipermedios.

El hipermedio es un concepto extensivo del de hipertexto (Caridad, Mercedes y Moscoso, Purificación, 1991, 48); hablando desde un punto de vista semiótico, podríamos determinar que en su esencia son lo mismo, lo que cambia es su forma de expresión y sus características físicas. Mientras que el hipertexto debería ser un concepto ceñido a la información textual, el hipermedio sería un archivo capaz de integrar información textual, visual, auditiva, animada y audiovisual.

En sentido estricto, Happing sería un hipermedio porque en el espacio web de Coca-Cola España, encontramos información de muy diversos tipos: visual, auditiva, audiovisual y textual, sin embargo, teniendo presente esta matización física, preferiremos referirnos a esta comunidad web como un gran hipertexto, en los tres aspectos que hemos comentado con anterioridad:

1. Desde una consideración electrónica: Sus características técnicas le convierten en el 
hipertexto soñado por Bush y Nelson. Happing es una enorme biblioteca de experiencias, sensaciones, sueños y pasiones, a la que puede acceder libremente cualquier persona que tenga acceso a Internet, al tiempo que tales personas pueden contribuir a su enriquecimiento. de la felicidad y sus consecuencias; la diferencia obvia es que, en el caso de CocaCola no estamos hablando sólo de literatura, de proverbios y frases transformadas de forma simple respecto a siglos anteriores en los que también se dieron para regresar con nuevo brillo y en forma de hipertexto de aquello que fueron, además hablamos de imágenes simbólicas. Colores y formas se reutilizan en la web de Coca-Cola España, para expresar sensaciones que simbolizaron eso mismo que connotan en Happing, pero en tiempos lejanos o en culturas antes más desconocidas.

El nativo digital que participa activamente en Happing no es un
2. Desde una consideración comunicativa: Happing, es una plataforma cibernética que elimina la linealidad del texto escrito, fomentando la existencia de un lector-autoractor, que además de seleccionar lo que lee, puede aportar algo a la construcción de ese texto comunitario (obra colectiva) como un participante activo en "la comunidad de la gente que se atreve a ser feliz".

Del mismo modo que Borges crea sus relatos mediante la reescritura de lo que él considera obras base de la literatura, CocaCola crea su marca conforme a la relectura mero lector que escoge, con un esfuerzo adicional y no trivial, un camino para su lectura durante su visita, además es autor de parte de ese texto colectivo si decide contribuir en él, aportando sus experiencias, sentimientos y visiones.

En este sentido, Happing se convierte en un cibertexto (Piscitelli, Alejandro, 2002), ya que permite una dimensión paraverbal estrechamente vinculada a los instrumentos que en el sitio web se ponen a servicio de los participantes para la producción del texto. Happing como el cibertexto, es un 
juego-mundo, donde uno puede perderse, descubrir caminos secretos y ofrece todo un abanico de posibilidades expresivas para los participantes en la comunidad.

3. Desde una consideración filosófica y cultural, Happing es:

- Según una reinterpretación de las consideraciones de Genette: Un hipertexto conceptual que se va reinventando y reescribiendo conforme a una idea que vuelve una y otra vez, que constituye el sol en torno al cual existe, no sólo Happing, sino la marca Coca-Cola: la expresión de la felicidad.

- Según una reinterpretación de las consideraciones de Lévy: La metáfora de un trabajo colectivo entre la máquina (el ordenador), la tecnología cibernética, la compañía Coca-Cola y los nativos digitales.

\section{Los creadores de ese gran hipertexto: nativos digitales}

Los nativos digitales son los seres humanos nacidos en la era de las últimas tecnologías de la información y la comunicación que se aventuran a crear esos hipertextos de los que ya hemos hablado, caracterizados por aunar las características técnicas con las que los definían Bush y Nelson y las peculiaridades comunicativas y literarias que apuntaron Landow y Genette.

\subsection{La idea de nativo digital}

La primera idea concreta sobre los nativos digitales la proporcionó Marc Prensky (2001) en su artículo Digital Natives, Digital Immigrants, en el que hacía referencia a la necesidad de cambiar las formas educativas en una sociedad que se encontraba ante nuevos estudiantes: los nativos digitales.
"Today's students - K through college represent the first generations to grow up with this new technology. They have spent their entire lives surrounded by and using computers, videogames, digital music players, video cams, cell phones, and all the other toys and tools of the digital age. (...). Computer games, email, the Internet, cell phones and instant messaging are integral parts of their lives.

What should we call these "new" students of today? Some refer to them as the N-[for Net]-gen or D-[for digital]-gen. But the most useful designation I have found for them is Digital Natives. Our students today are all "native speakers" of the digital language of computers, video games and the Internet." (Prensky, Marc, 2001). 
Marc Prensky (2001), se empeñó en diferenciar a estos nativos digitales de los que denominó inmigrantes digitales, incluyéndose en este segundo grupo de personas que, aunque forman parte de la era digital, nacieron en una etapa previa, viéndose obligadas a adaptarse al nuevo lenguaje impuesto no sólo por las técnicas digitales, sino por sus usuarios predilectos: los nativos digitales. Consideró que los nativos digitales tenían unas características muy determinadas entre las que cabe destacar:

1. Reciben información de forma casi inmediata.

2. Sienten predilección por los procesos paralelos (multitareas).

3. Prefieren el lenguaje visual (gráficos e imágenes) al textual.

4. Defienden los accesos al azar desde hipertextos.

5. Funcionan mejor cuando trabajan en red.

\subsection{El participante activo en}

\section{Happing, un nativo digital}

Si nos detenemos a examinar el perfil de usuario de Happing, nos será fácil determinar que se trata de un nativo digital:

1. Persona joven (menor de 30 años $y$, consecuentemente, nacida en las últimas décadas de siglo XX, en la era digital).

2. Necesariamente usuario frecuente $y$ asiduo de Internet: Si se ha pronunciado en un espacio cibernético es porque se consi- dera parte de él y, mencionada consideración exige una participación en ese mundo, que sólo es posible a través de este medio.

\section{Gráfico 3: Usuarios participantes en Happing}

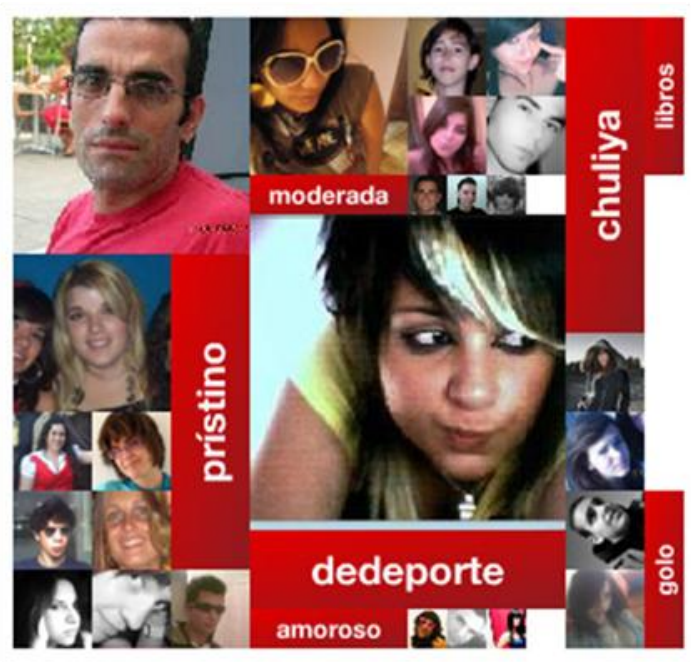

Fuente: Web de Coca-Cola

3. Amante de un ocio caracterizado por estar plagado de hipertextos a los que pueden acceder de forma paralela y simultánea.

4. Creadores de estos hipertextos que se construyen de forma comunitaria, a través de la red, utilizando un lenguaje donde la imagen tiene un peso indiscutible y los contenidos parecen distribuirse al azar, sin responder a un orden lógico de prioridades. La "gente que se atreve a ser feliz" responde, por tanto, al perfil de nativo digital que dibujó Marc Prensky en sus trabajos, determinándose como un creador-autorconsumidor de un conjunto de hipertextos que configuran el gran hipertexto (realmen- 
te hipermedio, por la confluencia de diferentes formas de leguaje) que es la comunidad Happing, en la que tales nativos partici- pan y a la que, en definitiva, pertenecen haciendo posible su existencia.

\section{Las estrategias para crear ese mundo mágico: entre el la web $2.0 \mathrm{y}$ el marketing viral}

Happing, la comunidad de la gente que se atreve a ser feliz, se convierte en un paraíso utópico y mágico que, fríamente analizado, no es más que una estrategia de emarketing que contribuye a pulir la Imagen Corporativa de Coca-Cola; estrategia para la que los nativos digitales constituyen una herramienta esencial, pues ellos la hacen viable, la dan forma, contenido, existencia y razón de ser.

\subsection{Happing, ¿un sistema web 2.0 ?}

La forma de construir, afianzar o pulir la Imagen de marca por la que ha apostado el gigante de los refrescos con Happing, cumple también las características propias del los sistemas Web 2.0. Se trata de un concepto cuyo término acuñó Tim O’Reilly en 2004, para referirse a la segunda generación Web, basada en comunidades de usuarios y una gama especial de servicios (redes sociales, blogs, wikis...) que fomentan la colaboración, interacción y el intercambio entre usuarios.

Happing, como sistema web 2.0, es "la comunidad de la gente que se atreve a ser feliz”, un punto de encuentro e interacción entre todos los usuarios que con sus expre- siones contribuyen a configurar parte de la Imagen (intencional) de Coca-Cola.

\subsubsection{El concepto web 2.0}

Las características fundamentales que, según O’Reilly (2005), debía cumplir una web para poder considerarse 2.0 estaban:

- Servicios, no software empaquetado, con escalabilidad rentable.

- Control sobre fuentes de datos únicos y difíciles de replicar que se enriquezcan a medida que más gente las utilice.

- Confiar en los usuarios como COdesarrolladores.

- Aprovechar la inteligencia colectiva.

- Sacar partido del autoservicio del cliente.

- Software no limitado a un solo dispositivo.

- Interfaces de usuario, modelos de desarrollo y modelos de negocio ligeros.

Un compendio de cualidades que perfilaban una definición muy técnica; sin embargo, Ian Davis (2005), sentenció Web 2.0 is an attitude not a technology, haciendo referencia a la necesidad de comprender el concepto como actitud que precisaba de la 
inteligencia colectiva, entendida como la capacidad del grupo para resolver problemas que cada individuo del colectivo, de forma personal, no sería capaz de resolver ni, incluso, de entender (Ribes, Xabier, 2007).

En un intento por fusionar ambas perspectivas, Xabier Ribes (2007), entiende como sistema 2.0, todas aquellas utilidades y servicios de Internet que se sustentan en una base de datos, la cual puede ser modificada por los usuarios del servicio, ya sea en su contenido (añadiendo, cambiando o borrando información o asociando datos a la información existente), bien en la forma de presentarlos, o en contenido y forma simultáneamente.

\subsubsection{La parte web 2.0 de Happing}

Happing, se adapta a todas estas cualidades en alguno de sus aspectos; en principio, lo tentador de la web 2.0, reside precisamente en la llamada producción bazar y la inteligencia colectiva que determinan un sistema de trabajo colectivo que no se muestra supervisado por la figura de una autoridad central que lo coordine. Sin embargo, en Happing, la compañía controla toda la información que se publica en la comunidad, filtrando -con alta probabilidad-, toda la información que no sea favorable a la construcción de una Imagen positiva para la marca.

En este sentido, existe un control del grupo (Ribes, Xabier, 2007) que a diferencia del control admitido en una web 2.0 (es la comunidad la que regula la propia producción del grupo), la compañía que hace posible la existencia de la comunidad (porque financia la plataforma) es la máxima autoridad, aunque trate de mantenerse latente y nunca haga manifiesto su dictamen, éste es omnipresente.

El motivo de este control, reside en el fondo de la razón de ser de Happing: es una estrategia de Comunicación Corporativa, emprendida por Coca-Cola con un objetivo único: beneficiar a su Imagen de marca. Esto convierte Happing en una forma de marketing cibernético o e-marketing.

\subsection{El marketing viral, otra de las posibilidades de Happing}

Dentro del e-marketing, el que, inicialmente más importancia a dado al usuario es el conocido como marketing viral. Ahora bien, ¿qué se entiende por marketing viral? En principio, es el término que se ha utilizado para la comunicación empresarial que trata de explotar redes sociales preexistentes con el fin de producir incrementos exponenciales en el conocimiento de una determinada marca, de tal forma que la difusión de la marca se produzca de manera similar a la propagación de un virus informático.

El marketing viral tiende a basarse en el boca a boca, aunque también es un término utilizado para referirse a campañas encubiertas a través de blogs o comunidades cibernéticas que difunden una historia im- 
pactante asociada a una idea directamente vinculada a una marca por un presupuesto muy inferior al de una campaña publicitaria ordinaria. Este segundo concepto de marketing viral, que no todos los autores identifican como tal, es al que respondería Happing.

\subsubsection{Un acercamiento al confuso concepto del marketing viral}

El concepto de marketing viral corresponde, según la mayoría de los autores, a Steve Hurveston, quien utilizó el término por primera vez en 1997, durante una conferencia, para referirse a la práctica de promoción que determinados servicios libres de correo electrónico utilizaban, añadiendo su propia publicidad al correo saliente de sus usuarios.

Sin embargo, el primero que escribió sobre el marketing viral fue Douglas Rushkoff, en 1994 y en su libro Media Virus. Rushkoff consideraba que el marketing viral consistía en el contagio de una serie de usuarios sensibles a una determinada idea publicitaria, de tal modo que tales usuarios infectados pudiesen, a su vez, contagiar en cadena a otros muchos usuarios sensibles.

Una de las definiciones más estables e interesantes del marketing viral es la de Ralph F. Wilson (2000, 2005, 2007):

"Viral marketing describes any strategy that encourages individuals to pass on a marketing message to others, creating the potential for exponential growth in the message's expo- sure and influence." (Wilson, Ralph F., 2007, original 2000).

Definición que resuelve muy bien Lourdes Castillo (2000), al determinar las claras semejanzas que existen entre el marketing viral y la expansión de un virus: el marketer "suelta un virus y lo deja que se propague por sí solo, igual que como sucede con los virus que tientan contra nuestra salud, sólo que en este caso los virus son buenos, pues al propagarse ayudan a dar a conocer nuestra marca. Por eso Internet es un medio muy propicio para la transmisión de este marketing, dado que facilita las comunicaciones a distancia y paralelas, de un emisor a múltiples receptores.

Roberto Neuberger (2000), aclara una definición parecida a las aquí recogidas, estableciendo que [el marketing viral] es publicidad que se propaga así misma y constituye la mejor forma para iniciar la rodada en los medios, por lo que resuelve que podría llamarse estrategia de apalancamiento en los medios.

En esta misma línea, Enrique de la Rica (2006, 268) explica que el término viral procede del proceso de difusión que utiliza este tipo de e-marketing, ya que se propaga según una espiral viral que se compone de un e-mail que por alguna razón (su contenido es gracioso, emotivo, sorprendente, impactante...) es reenviado de un buzón a otro.

Como podemos observar, existen muchas definiciones de marketing viral, veremos 
que también hay muchos tipos, pero existen unas bases o principios que vienen a definir una estrategia eficaz de marketing viral; según Ralph F. Wilson (2007), son seis principios:

1. Ofrecer un producto o servicio de valor para los usuarios: Las ganancias deben dejarse para más adelante, al principio hay que captar al cliente con un servicio o producto atractivo y gratuito.

2. Facilitar un medio de difusión sencillo: Un virus sólo puede expandirse cuando es fácil de transmitir; por eso Internet es un buen medio para este tipo de marketing.

3. El servicio ofrecido debe ser fácilmente escalable: Debe ser un servicio estable, capaz de soportar un crecimiento exponencial muy rápido.

4. Aprovechar y explotar la motivación y los comportamientos humanos: Sería recomendable que el servicio pudiese explotar sentimientos de pertenencia, status, popularidad,...

5. Utilizar las redes existentes de comunicación: El ser humano, en cuanto a ser social, se mueve en círculos comunitarios de personas (amigos, familiares, compañeros,...) y, según su posición en la sociedad, puede tener influencia en otras muchas personas; si la campaña de marketing aprovecha estas redes sociales, el contagio se logrará de forma rápida y eficaz y el objetivo será alcanzado.

Estas redes sociales son el objeto realmente valioso del marketing viral; para el marke- ting de tercera generación, los productos no importan, importan las relaciones, de ellas puede sacarse más provecho.

6. Tomar ventaja de los recursos ajenos.

Enrique de la Rica (2006) apunta dos características muy interesantes que siempre acompañan a las campañas de marketing viral: la multidifusión por e-mail y la polémica (De la Rica, Enrique, 2006, 262-266), haciendo referencia a dos conocidos ejemplos (Nike y Volkswagen Polo) que resultaron un éxito para las marcas protagonistas, pero no las dejaron fuera de una importante polémica que siempre puede resultar contraproducente.

En función de cada autor y considerando que en su forma originaria el marketing viral podría llevarnos a reducirlo a una versión cibernética del boca a oído (o boca a boca), Wikipedia nos proporciona todo un abanico de posibilidades de difusión que determinarían diferentes formas de marketing viral:

1. Pásalo: Consiste en alentar al usuario a pasar un mensaje a otros usuarios sensibles. Un ejemplo claro de este tipo de comunicación viral lo constituyen los correos en cadena o los anuncios televisivos que un usuario reenvía a varios amigos porque le han impactado de algún modo (bien le han parecido graciosos, bien le han sensibilizado, bien le han parecido violentos...).

2. Incentivado: Es el mensaje viral que incluye una recompensa al usuario por contribuir a la infección, es decir, por faci- 
litar direcciones de e-mail a las que difundir el mensaje.

3. Marketing encubierto: En este caso el mensaje se presenta en formato de página web, blog o comunidad on line, y da a conocer una noticia atractiva e impactante que, a veces requiere la participación del usuario. Aparentemente no es marketing viral, porque no existe, explícitamente una difusión del mensaje de un usuario a varios, es más, se pone especial cuidado en que el usuario sienta que ha descubierto espontáneamente el sitio web a través de una serie de pistas que se le van dejando en otros portales y van generando un misterio que el usuario pretende desvelar.

4. Marketing del rumor: Son mensajes basados en noticias de dudosa veracidad, morbosas y controvertidas, basadas en la conocida técnica de difusión del boca a boca y que con tanta frecuencia se utilizan en la prensa sensacionalista.

Existen otras formas y cada vez surgen otras más, pero éstas son las más destacadas en el marketing viral y la que aquí nos interesa es la tercera, pues Happing es una campaña de marketing viral encubierto.

Además de los tipos de marketing o comunicación viral, éstos pueden mostrarse de diferentes formas; entre los diferentes métodos posibles (Claudio Ariel Clarenc (2007), propone hasta 12 ideas para difundir viralmente una campaña de marketing), nosotros destacaremos sólo 5:
1. Web a Boca: Transmisión de un mensaje concreto que aparece en una web determinada a uno o varios usuarios (amigos o conocidos) desde la propia web. Existen páginas de diarios on line o revistas o agencias que permiten enviar una noticia o una oferta a un amigo.

2. Email a Boca: Se trata de reenvío de mensajes de correo, ya sean chistes, fotos, pasatiempos, cadenas...

3. MI a Boca: Consiste en el envío de hiperenlaces mediante el uso de programas de mensajería instantánea (MI-Instant Messaging). Tal vez el más conocido y utilizado sea el MSN, utilizado por mucha gente joven que cumple el perfil de nativo digital.

4. Boca a Boca: La correcta traducción a nuestro idioma sería el boca a oreja, pues se trata de una técnica consistente en pasar información por medios verbales (esencialmente recomendaciones, aunque también información de carácter general) y de modo informal y personal. No obstante $\mathrm{y}$, aunque sea una forma de comunicación fundamentalmente hablada, los diálogos en Internet (blogs, foros, e-mail, Messenger), tienden a incluirse en el seno de este concepto que forma parte del marketing de tercera generación, en el que lo esencial ya no son los productos, sino las relaciones.

5. Bluetooth: Este dispositivo instalado en los teléfonos móviles permite la transmisión gratuita de mensajes de todo tipo entre los terminales de los diferentes usuarios. 
Sin embargo, el marketing viral, también choca con barreras que si no impiden su transmisión, si la vienen a dificultar. Entre los grandes antivirus, para este tipo de marketing, se puede destacar:

1. El tamaño del mensaje: Si la difusión utilizada para la transmisión del mensaje viral es Internet, el tamaño del mismo deberá ser limitado, especialmente cuando se utilice el correo electrónico para la distribución de la información viral.

2. El formato en el que se presente: El mensaje viral deberá presentarse en un formato extendido para que la mayoría de la gente pueda acceder a él.

3. Los sistemas de seguridad instalados en el PC del usuario: A veces, un usuario no puede abrir un mensaje viral o acceder a un sitio web en el que se exponga porque software de su ordenador (antivirus y firewall), se lo impiden.

4. La complejidad del formato: Si una campaña de marketing viral se presenta en un formato complicado de utilizar y poco atractivo, estará condenada al fracaso, porque el usuario no entrará, jamás, a participar en algo que no le guste y el marketing viral exige la participación del usuario para que la campaña sea posible.

5. La apariencia de la campaña: La campaña además de sencilla y atractiva deberá no parecer tener una clara intención comercial, pues si el usuario descubre que se trata de comunicación corporativa puede, no sólo rechazarla sino incitar a otros usuarios a que también la rechacen; se produciría entonces un boicot o sabotaje de la campaña que la harían desembocar en el fracaso.

Además de este tipo de boicot, existe otro más directo, ejecutado por alguno o varios de los receptores del mensaje sobre el contenido del mismo, modificando así el significado de la campaña en perjuicio de la marca. Se trata de aquello a lo que Lourdes Castillo (2000) se refería al decir que, en la transmisión del virus, éste puede mutar y, en lugar de beneficiar a la marca, perjudicarla.

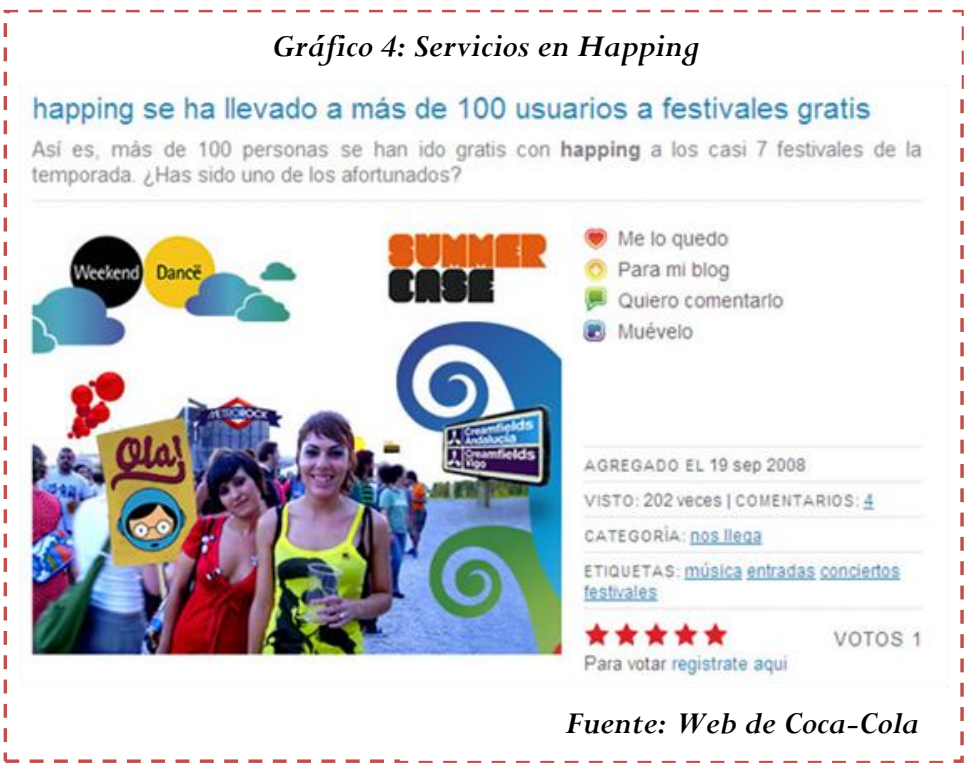


Como apunta Jonathan Levenzon (2001) en su artículo Marketing viral, esta estrategia comunicativa tiene limitaciones y quien la aplica debe ser muy consciente de ellas. No puede viralizarse cualquier campaña, sólo las que satisfagan los principios establecidos por Wilson son propicias para ser virales.

\subsubsection{La parte viral de Happing}

Como ya hemos mencionado, Happing correspondería al marketing encubierto, aunque Enrique de la Rica ofrece una terminología, en mi opinión más precisa, la de Weblog Corporativo (De la Rica, Enrique, 2006, 269) y, aún sería preferible hablar, según mi criterio, de una Comunidad Corporativa.

El potencial de estas comunidades, construidas como espacios interactivos y multimedia en una versión visualmente cuidada de los foros y los blogs, han impulsado una forma de marketing viral (porque su atractivo contagia a los usuarios) encubierto (porque no se muestra en cuanto a tal) que consiste en que la marca (en nuestro análisis, Coca-Cola), escuche lo que se está diciendo en la Red sobre ella.

Happing permite a Coca-Cola, reforzar su marca y acceder a una información muy interesante: la que le ofrecen todas las conversaciones que se producen en su web; al mismo tiempo, "la comunidad de la gente que se atreve a ser feliz", permite desarrollar nuevas relaciones no sólo entre los consumidores, sino también entre la compañía de refrescos y sus clientes; en estas características reside el atractivo de Happing y su viralidad, es decir, el que unos usuarios se contagien de la emoción de participar en la creación de un discurso.

Entre los principios básicos que consideró Ralph F. Wilson (2007) y que satisface Happing como comunicación contagiosa, podemos detectar los siguientes:

1. El servicio gratuito que se ofrece es de un valor, casi incalculable, para sus usuarios: Se les permite la posibilidad de expresar libremente su felicidad, vinculando todo ideal de libertad al de felicidad y pertenencia a la marca Coca-Cola. Pero además incentiva a los participantes en el blog regalando entradas para festivales como el MetroRock y no deja de comunicar esos regalos desde la misma web. 2. El medio de difusión, Internet, es muy sencillo para usuarios que han nacido en su expansión globalizada.

3. Coca-Cola explota, en Happing, la motivación de alcanzar el sentimiento más soñado de todos los posibles, la felicidad; para ello, motiva al usuario permitiéndole exponer posibles fragmentos del largo camino que es necesario recorrer para alcanzar, aunque sea con la punta de los dedos, un sentimiento para muchos inalcanzable $y$ utópico.

Las estrategias de motivación son varias:

a) Confirmación de pertenencia a la "comunidad de la gente que se atreve a ser feliz".

b) La posibilidad de contribuir a crear "felicidad". 
c) El estatus de protagonista-creador del discurso de Coca-Cola y la cierta popularidad que ello conlleva, aunque se reduzca al pequeño universo de Happing, la compañía de refrescos fomenta la motivación y da rienda suelta a la creatividad de los nativos digitales que se atreven a soltarla.

4. Happing aprovecha redes sociales, al tiempo que favorece una nueva relación comunicativa entre nativos digitales. La relación preexistente entre los jóvenes comunitarios puede ser muy diversa: pueden ser amigos, familia, compañeros de clase, vecinos en el barrio, compañeros de aficiones, etc.

Este tipo de relaciones puede llevar a uno de estos jóvenes a contagiar a esos otros con los que comparte aficiones u otro tipo de motivaciones, de la emoción de participar en la comunidad, por lo que no resulta aventurado pensar que Coca-Cola aproveche estas redes preexistentes para extender y popularizar los ideales que sientan las bases de su marca: atrevimiento y felicidad.

Sin embargo, muchos de estos jóvenes afines, pueden conocerse a través de Happing, por lo que "la comunidad de la gente que se atreve a ser feliz", se convierte en catalizador de relaciones sociales entre personas de un perfil determinado: Jóvenes nativos digitales, atrevidos, creativos, alegres, idealistas y soñadores -aunque su capacidad para soñar e imaginar puede estar motivada por su corta edad-.
La diferencia fundamental que podemos percibir entre este tipo de marketing viral y el frecuentemente conocido como tal (el boca a boca o boca a oído), es que en el caso de Happing no se utiliza el mail para la difusión del mensaje y el boca a boca se produciría fuera de la propia web; en este caso no es el mensaje el que llega al usuario, sino que debe ser el usuario el que acuda a la plataforma, bien por la recomendación expresa de otro usuario (que puede ser su amigo, compañero, primo, hermano, etc.), bien por su propia iniciativa, movido por la curiosidad y la fascinación que suscitan los weblogs.

El potencial vírico de Happing reside en los siguientes aspectos:

1. Coca-Cola, convierte al usuario en creador-protagonista de la comunidad que la marca avala: A través de Happing, el consumidor no sólo se siente escuchado, sino también, creador y protagonista de un discurso que, aunque propiedad de CocaCola, no sería posible sin él; se siente así importante, porque Coca-Cola le ha convertido en parte significativa de la marca.

2. Coca-Cola no sólo se aprovecha de redes sociales preexistentes, además motiva la creación de otras nuevas: A través de Happing, los usuarios comparten contenidos creando un mundo nuevo en torno a la idea de la felicidad; idea patrocinada por una marca que, aunque sutilmente, siempre está presente, buscando, no tanto dar a conocer un producto como lograr asociar la felicidad a sus productos y su concepto de 
marca (Imagen Corporativa de Coca-Cola), fomentando relaciones alegres y positivas que contribuyan a su propósito último.

3. Coca-Cola utiliza Happing como una estrategia de marketing para beneficiar a su propia Imagen, pero lo hace muy sutilmente: Videos, música, flash, imágenes y textos se combinan en lo que, aparentemente es un espacio patrocinado por Coca-Cola para el disfrute de sus usuarios; lo que estos consumidores parecen no vislumbrar claramente es que están trabajando gratis en el pulido de la Imagen de la Compañía de refrescos.

Usuarios y marca se manifiestan conformes y contentos con los resultados de una campaña de este tipo; los usuarios porque tienen una plataforma de expresión que les permite contribuir a crear una comunidad a la que, al mismo tiempo pertenecen - "la comunidad de la gente que se atreve a ser feliz"-; la marca, porque logra hacer una campaña a muy bajo coste, sólo necesita un dominio, una idea y una comunidad de nativos digitales que la explote.

El bajo coste del marketing viral es lo que alienta a las marcas para apostar por él; sus limitaciones más importantes residen en el perfil de su público. Aunque el marketing viral no se ha centrado exclusivamente en Internet, también se han dado campañas en otros medios, lo cierto es que tiende a cautivar más a un público joven con predilección por las Nuevas Tecnologías de la Información y la Comunicación (NTIC) - nativos digitales- que a cualquier otro tipo de público.

Si mencionada revolucionaria fórmula de hacer marketing consiste en el aprovechamiento de redes sociales preexistentes para difundir una idea atractiva que el gran público pueda asimilar a la Imagen de una marca, hemos de determinar que, efectivamente, los nativos digitales son fundamentales para la existencia de tal forma de Comunicación Corporativa.

Ahora bien, ¿cómo un nativo digital, narrando sus experiencias, recurriendo a las diferentes formas de expresión que la web les permite -colgando videos sobre momentos especiales de su vida, subiendo fotos, resumiendo en una frase una determinada sensación, escribiendo en un blog comunitario, etc.- pueden contribuir a la Imagen de Coca-Cola? la respuesta reside en el concepto mismo de Imagen Corporativa y en todas las consideraciones que hemos hecho sobre el hipertexto-hipermedio que es Happing.

\subsection{Happing, el refuerzo perfec- to para una Imagen positiva}

La Imagen Corporativa de una empresa o corporación es el concepto que nosotros, como público, creamos de ella en nuestras mentes, a partir de todas las informaciones que recibimos de ella o sobre ella, tengan o no voluntad comunicativa. Esta es la definición más completa y clara que podemos extraer de las definiciones que ofrecen dos 
grandes expertos en el ámbito de la Comunicación Corporativa:

"La Imagen Corporativa es la integración en la mente de sus públicos de todos los inputs emitidos por una empresa en su relación ordinaria con ellos”. (Villafañe, Justo, 1999:30).

"La Imagen Corporativa es la representación mental, en el imaginario colectivo, de un conjunto de atributos $y$ valores que funcionan como un estereotipo y determinan la conducta y opiniones de esa colectividad". (Costa, Joan, 2001:58).

Por la definición, parece imposible un absoluto control en la creación de este concepto y, en efecto, lo es. El público construye la Imagen de Coca-Cola a partir de toda la información que recibe de y acerca de la compañía, especialmente si no tiene voluntad comunicativa o si aparentemente no existe tal voluntad. Por eso, es vital que las empresas controlen, en la medida de lo posible, lo que dicen y lo que hacen, especialmente si no tiene voluntad comunicativa, porque lo que más dice es lo que se hace y no se quiere decir que se ha hecho.

Sin embargo, existe una parte de la Imagen Corporativa, que sí es intencional (Villafa- ñe, Justo, 1999) y que la empresa puede controlar, cuidando su Comunicación Corporativa y su Identidad Visual Corporativa. Ahora bien, ¿entra Happing en este control? Pues sí, totalmente, para decepción de algunos "atrevidos a ser felices".

Happing es una estrategia controlada de Comunicación Corporativa; aunque puede parecer una plataforma de expresión libre para los nativos digitales que la constituyan, no es posible pensar que Coca-Cola permita una expresión fuera de las líneas que deben perfilar una Imagen Corporativa positiva.

El nativo digital al participar activamente en la comunidad de la gente que se atreve a ser feliz, está contribuyendo a construir y/o pulir el estereotipo que tenemos de CocaCola; se convierte, por tanto y en parte, en creador activo de la Imagen Corporativa Intencional de la empresa.

Además, los nativos digitales que se expresan en Happing, manifiestan una conducta positiva (la compañía no permitiría una conducta negativa en su contra) hacia la marca que patrocina la plataforma en la que se expresan y se relacionan con personas que comparten e intercambian opiniones y experiencias.

\section{Conclusiones}

- Happing es una especie de Aleph, en el que no tienen cabida ni las desgracias ni, tan siquiera, la realidad; se trata de un mundo mágico financiado por Coca-Cola para la gente que se atreve a ser feliz; este mundo mágico encierra un nuevo lenguaje y una nueva forma de ocio, pero exige la existencia de nativos digitales sin los cuales no sería posible. Sentimientos, sensaciones, experiencias... de estos nativos, configuran 
un universo cargado de valores positivos que relacionar con la marca de la compañía que financia la plataforma.

- Happing es un hipertexto:

- En su interpretación técnica y electrónica, porque puede considerarse una rica biblioteca de experiencias, sensaciones, pasiones, atrevimientos y diversiones a las que puede acceder todo el que posea conexión a Internet.

- En su interpretación comunicativa, porque constituye como un gran texto en el que se elimina la linealidad del texto escrito tradicional y se permite al usuario-lector, ser también coautor del mismo, facilitándole todo un conjunto de posibilidades expresivas que dotan a este texto de la dimensión paraverbal propia de los cibertextos.

- En su interpretación filosófica y cultural porque, por un lado es una constante reinterpretación de la idea de la felicidad y, por otro lado porque puede considerarse la metáfora de un trabajo colectivo en el que participa Coca-Cola, los usuarios de Happing, los ordenadores y la tecnología cibernética.

- Los creadores de Happing son nativos digitales que satisfacen las características determinadas por Marc Prensky:

- Son jóvenes nacidos en la era digital.

- Usuarios frecuentes y asiduos de Internet.
- Amantes de un ocio plagado de hipertextos a los que pueden acceder de forma paralela y simultánea.

- Creadores de estos hipertextos en los que la imagen tiene un peso indiscutible y los contenidos parecen distribuirse al azar, sin responder a un orden lógico de prioridades.

- Happing es una comunidad que responde, en parte al sistema web 2.0, ya que, aunque se muestre como una plataforma de "expresión libre para la gente que se atreve a ser feliz", lo cierto es que todo lo que se publica está controlado por la compañía que financia la comunidad. El control de CocaCola, aunque latente es omnipresente, pues Happing es una estrategia de Comunicación Corporativa.

- Happing contiene un potencial vírico que puede llevarnos a considerarlo marketing viral encubierto. Ese potencial vírico reside en tres puntos clave:

- Coca-Cola, convierte al usuario en creador-protagonista de la comunidad, haciéndole parte significativa de la marca.

- Coca-Cola no sólo se aprovecha de redes sociales preexistentes, además motiva la creación de otras nuevas.

- Coca-Cola utiliza Happing como una estrategia de marketing para beneficiar a su propia Imagen, pero lo hace tan sutilmente, que el usuario no se da cuenta de que está trabajando gratis en la creación de una Imagen positiva para la 
marca de refrescos; es más, llegan a sentir gratitud hacia la compañía porque les facilita una forma de expresión que les agrada.

Usuarios y marca se manifiestan satisfechos con los resultados de una campaña de este tipo; los usuarios porque tienen una plataforma de expresión gratuita y la marca, porque logra hacer una campaña creativa a muy bajo coste.
-Happing es, por encima de todo, una estrategia controlada de Comunicación Corporativa.

Coca-Cola controla todo lo que se publica en Happing, aunque nunca manifieste su autoridad, debe llevar a cabo este control, pues de él depende la adhesión de su Imagen a valores positivos o negativos.

\section{Referencias}

AARSETH, E. (1997) Cybertext: Perspectives on Ergodic Literature, The Johns Hopkins University Press, Baltimore.

AARSETH, E. (2006) Sin sensación de final: La estética hipertextual, en AAVV. Teoría del hipertexto. La literatura en la era electrónica, Arco Libros, Madrid.

ALAZRAKI, J. (1984) El texto como palimsesto: Lectura intertextual de Borges, Hispanic Review, 52:3 (1984:Summer) p.281-302.

BORGES, J.L. (1972) Los cuatro ciclos en El oro de los tigres, Emecé, Buenos Aires.

BORGES, J. L. (2002) El Aleph, Alianza Editorial, Madrid.

CARIDAD, M. y MOSCOSO, P. (1991) Los sistemas de hipertexto e hipermedios. Una nueva aplicación en informática documental, Fundación Germán Sánchez Ruiperez, Madrid.

COLINA, C. (2002) El lenguaje de la Red. Hipertexto y Postmodernidad, Universidad Católica Andrés Bello (UCAB), Caracas.

COSTA, J. (2001) Imagen Corporativa en el siglo XXI, La Crujía Ediciones, Buenos Aires.

DE LA RICA, E. (2006) Marketing en Internet, Anaya Multimedia, Madrid.

GENETTE, G. (1989) Palimpsestos. La literatura en segundo grado, Taurus, Madrid.
LANDOW, G. (1997) Teoría del Hipertexto, Paidós, Barcelona.

VILLAFAÑE, J. (1999) La gestión profesional de la imagen corporativa, Pirámide, Madrid.

PISCITELli, A. (2002) Ciberculturas 2.0. En la era de las máquinas inteligentes, Paidós, Buenos Aires.

PISCITELLI, A. (2002) El eclipse de los medios en la era de Internet, La Crujia, Buenos Aires.

PRENSKY, M. (2001) Digital Natives, Digital Immigrants, en On the Horizon, NCB University Press, Vol $9 \mathrm{~N}^{\circ} 5$.

\section{Webgrafía}

Los diferentes artículos y documentos on line consultados, analizados y/o citados para la elaboración del éste trabajo y cuya referencia se describe a continuación, se han visitado en varias ocasiones desde julio de 2008 hasta octubre de 2008.

BUSH, VANNEVAR, Julio de 1945, As we may think, en Athlantic Monthly, $\mathrm{N}^{\circ}$ 176, 101-108.

http://www.theatlantic.com/doc/194507/bush

CERRADA, ROBERTO R., ¿Conoces El Efecto Bola De Nieve? Marketing Viral: Un Método Para Hacer Explotar Tu Negocio En Internet. http://www.marketinginteligente.com/ecm.php?IIttem $=8$ http://www.ldc.usb.ve/ abianc/hipertexto.html CLARENC, CLAUDIO ARIEL, 20 de Julio de 2007. 12 ideas de marketing para difundir y promocionar su negocio en Internet. 
www.conectarnos.com/blog/2007/07/20/12-ideas-demarketing-para-difundir-y-promocionar-su-negocio-eninternet/

DAVIS, I., Julio de 2005, Talis, Web 2.0 and All That, en Internet Alchemy

http: / / iandavis.com/blog/2005/07/talis-web-20-and-allthat

GARCÍA GARCÍA, FRANCISCO, Marzo 2006, Contenidos educativos digitales: Construyendo la Sociedad del Conocimiento, en Red Digital. Revista de Tecnología de la Información y la Comunicación Educativas, $\mathrm{N}^{\circ} 6$ http://reddigital.cnice.mec.es/6/Articulos/articulo_resu men.php?articulo $=1$

http:/ / es.wikipedia.org/wiki/Boca_a_boca

http://es.wikipedia.org/wiki/Marketing_viral

LEVENZON, JONATHAN 2001, Marketing viral. http://articulos.astalaweb.com/Marketing\%20viral/1_Ma rketing\%20viral.asp

NELSON, THEODORE, Deep Hipertext: The Xanadu Model http: / /xanadu.com/xuTheModel

NEUBERGER, ROBERTO, 25 de Octubre de 2000, Los 6 principios del marketing viral.

http://www.webtaller.com/maletin/articulos/los-6principios-del-marketing-viral.php

O'REILLY, TIM, Septiembre de 2005, What Is Web 2.0. Desing Patterns and Business Models for the Next
Generation of Software.

http://www.oreillynet.com/pub/a/oreilly/tim/news/20 05/09/30/what-is-web-20.html?page $=1$

ORTOLANO, MARIEL, 2006. Hacia una redefinición del concepto de hipertexto, Ponencia para las Séptimas Jornadas Nacionales de Literatura Comparada, Asociación Argentina de Literatura Comparada (AALC), Buenos Aires, 27 al 30 de julio de 2005.

http:/ / cultura.wordpress.com/2008/05/15/hacia-unaredefinicion-del-concepto-de-hipertexto/

RIBES, XAVIER, Octubre-Diciembre 2007, La Web 2.0. El valor de los metadatos y de la inteligencia colectiva, en Telos. Revista de Comunicación, Tecnología y Sociedad, $\mathrm{N}^{\circ} 73$.

www.campusred.net/TELOS/articuloperspectiva.asp?idart iculo $=2 \&$ rev $=73$

SCOLARI, CARLOS, Septiembre de 2003, Qué es un hipertexto?, en Clicks Modernos, $\mathrm{N}^{\circ} 5$.

http://www.dialogica.com.ar/clicsmodernos/2003/09/5 _que_es_un_hipertexto.html

WILSON, RALPH F., 18 de Mayo de 2001 (original en 2000), The Six Simple Principles of Viral Marketing. http:/ / mercadeo-viral.blogspot.com/2007/05/sixsimple-principles-of-viral.html

www.cocacola.es

\section{Cita de este artículo}

Llorente, C. (2009) Happing: Nativos digitales al servicio de la imagen corporativa de Coca-Cola. Revista Icono14 [en línea] 1 de junio de 2009, № 12. pp. 73-100.

Recuperado (Fecha de acceso), de http://www.icono14.net 